\title{
DE RECHTSVRAAG DER CHRISTENVERVOLGINGEN IN HET ROMEINSCHE RIJK OMSTREEKS HET. JAAR 200
}

Tertullianus, de felle iurisconsultus te Carthago, na zijn studietijd, dien hij te Rome had doorgebracht, Christen geworden, schreef in 197 zijn Apologeticum - naar sommige handschriften Liber apologeticus ter verdediging van de Christenen. Daarvóór had hij Ad nationes geschreven, in het Apologeticum meermalen gebruikt, een defensio, die telkens neerkomt op een beschuldiging tegen de heidenen en in het tweede gedeelte een critiek op de Romeinsche godenvoorstellingen. In denzelfden tijd, dan wel 5 of 6 jaar later valt zijn aangrijpende, eenerzijds uiterst scherpe, anderzijds wonderbaar troostrijke aansporing Ad martyres. Alles in den tijd van k. Septimius Severus (193-211), die in het jaar 202, toegevende aan den volkshaat, vrij omvangrijke vervolgingen den teugel liet, den overgang tot Jodendom of Christendom van Romeinsche burgers als een strafbaar feit behandelde en bekeerders zoowel als bekeerlingen deed opsporen en oordeelen.

Tertullianus beleefde, dat de religie, waarin hij de waarheid had gevonden, werd miskend en bestreden. Het laatste was voor hem als discipel van Jezus Christus begrijpelijk, het eerste verdroeg hij niet. Daarom zeide hij (Ap. I, 2) in zijn bijna onvertaalbare subjectieve en praegnante latijn, dat door elke overzetting onvermijdelijk iets, misschien veel van zijn kleur en doordringendheid verliest: de waarheid smeekt niets voor haar zaak af, want zij verwondert zich ook niet over de situatie, waarin zij gebracht wordt. Zij weet als vreemdelinge op aarde te verkeeren en dat $z i j$ onder buitenstaanders allicht tegenstanders ontmoet, maar zij weet ook haar vetwantschap, haar burgerschap, haar hoop, haar aanzien en plaats in den hemel te hebben. Eén ding intusschen streeft zij na, d.i. om niet zonder gehoord te zijn veroordeeld te worden.

Dit is het eerste formeele appèl, dat Tertullianus hier tot de praesides, de imperii romani antistites, de stadhouders met rechtsmacht van het Romeinsche Rijk richt. Hij vraagt om gerechtigheid, niet om genade, niet om tolerantie in het algemeen, maar om recht en wel tegenover de onhoudbare gronden, waarop de veroordeeling van het Christendom of de Christenen steeds blijkt te berusten. Bij een onderzoek onlangs geschied, was gebleken dat de ten toppunt gestegen haat tegen dezen godsdienst alle mogelijkheid zelfs van verdediging afsloot. Wij kennen dit geval niet. Maar het deed bij Tertullianus den emmer overloopen, hij greep opnieuw naar de pen en begon zijn even vurig als zakelijk en snijdend pleidooi, waarvan geest en methode in den Reformatietijd weer zouden herleven en dat menige trek bevat, die wij gedurende den bezettingstijd van ons land weder als radicale waarheid zijn gaan zien. 
Op welke manier gaat Tertullianus nu te werk? Klaar blijkt uit het Apologeticum, aldus een der laatste en beste commentatoren, ${ }^{1}$ ) dat er een wet bestond, een keizerlijk edict dan wel een senatus consultum, onder Nero uitgevaardigd (IV, 4; V, 3; Scorpiace, 15) en gedurende de eerste twee eeuwen meermalen hernieuwd of bevestigd, die op straffe des doods verbood Christen te zijn: non licet esse vos (Ap. II, 6; V, 4). De eenige misdaad door deze wet gestraft, de eenige, waarom Christenen voor het gerecht gesleept worden, de eenige, waarop de rechter zijn onderzoek richt en de eenige, die hij in het doodsvonnis aanvoert, is het feit, dat iemand Christen is en er in volhardt het te blijven: Christianus sum.

Hoe kan men een dergelijke wet verantwoorden en rechtvaardigen? Rome placht zich welwillend of tenminste tolerant te betoonen ten opzichte van vreemde goden; men begunstigde hun cultus in het openbaar (XXV, 4-7; IX, 2, 10), identificeerde hen met de eigen goden of liet op zijn minst aan de provincies, de civitates en de particuliere personen de vrijheid, hen naal eigen verkiezing te vereeren (XXIV, 7, 8). Wanneer Rome een vreemden cultus of exotische ceremoniën verbood, dan was dat niet uit religieuze motieven, maar met het oog op de openbare veiligheid of zedelijkheid en dikwijls gold het verbod ook slechts voor een bepaalden tijd (VI, 8, 10; IX, 2-5).

Niet op gronden van werkeliike bezwaren van den bedoelden aard, maar slechts verdacht ervan, was het Christendom van den beginne aan een verboden godsdienst. Men was er algemeen van overtuigd, dat het een superstitio exitiabilis was, malefica, prava, immodica, gepaard gaande met niet te noemen misdadigheid (flagitia nomini cohaerentia, Plin.; per flagitia invisos, Tac.). Sedert Nero stond vast, dat de Christenen het menschdom haten. En aangezien nu de wet den Christen $\mathrm{n}$ a a m strafte, namen de rechters de moeite niet om een onderzoek in te stellen naar de misdaden, waarvan vaststond, dat ze aan dezen naam kleefden en de laster had vrij spel. Mettertijd werd deze steeds meer omschreven. Het publiek geloofde in de 2 de eeuw, dat tot den Christenlijken inwijdingsritus het offer van een pas geboren kind behoorde, waarvan de nieuweling en degenen, die er bij tegenwoordig waren, het bloed dronken, en voorts maaltijden gevolgd door woeste orgieën (VII-IX). Desondanks verbreidde het Christendom zich met toenemende snelheid. In het begin der 2 de eeuw moest Plinius, de stadhouder van Bithynië, constateeren, dat in zijn ambtsgebied de tempels leeg liepen en Tertullianus zegt, dat aan het einde der 2 de eeuw zoowel het Rijk als de barbaren grootendeels voor het nieuwe geloof gewonnen waren (I, 6; XXXVII, 4-7; de overdrijving doen wij er af). Celsus bevestigt deze mededeelingen. ${ }^{3}$ ) In deze snelle toename zag men een groot gevaar

1) J. P. Waltzing, Tertullien, Apologétique, Paris 1931, Introduction.

2) TAcitus, Ann. XV, 44; Suetonies, Vita Neromis 16; Plinius de jongere, Ep. 1I, 96, 8.

2) Origenes, c. Celsum, III, 73. 
voor den Romeinschen godsdienst. Men zag er ook een bedreiging in van het Rijk, welks constitutie in zekeren zin nu eenmaal op godsdienstigen grond was komen te staan: de goddelijkheid van den keizer, en juist deze aard der aristocratische constitutie verdroeg zich niet met het Christendom; een Christelijke caesar werd door de Christenen zelf als een ondenkbaarheid beschouwd (XXI, 24).

„Op lieden, die zoo aller haat verdienden om hun misdrijven en zoo gevaarlijk waren voor godsdienst en Rijk, paste men een radicaal middel toe: non licet esse vos. Het feit op zich zelf van Christen te zijn is met den dood strafbaar. Dit wettelijk verbod richtte zich dus tegen den Christennaam: nominis proelium, ipsum nominis odium (Scorpiace 10 en Ap. II, 19). De aanduiding van de misdaad door deze wet gestraft, was geen andere dan het woord: Christianus. Deze wet had ten doel om de Christenen uit te roeien en de verdere verbreiding van de als misdadig en verderfelijk beschouwde secte te beletten (II, 20). - Zoo is het aan den anderen kant ook te begrijpen, dat sedert Trajanus de afval of verloochening voldoende was om vrijspraak te verkrijgen, zonder dat er dan verder op de beschuldigingen ingegaan werd, en dat men zelfs foltering toepaste om deze verloochening af te dwingen (II, 11). De rechters maakten zich niet de minste zorgen om de beschuldigingen, waar het volk mee kwam aandragen en die de wet rechtvaardigden, te onderzoeken. Zij werden als notoir beschouwd. Voor alle heidenen was "Christen" synoniem met een mensch, in staat tot alle afschuwelijkheden, een vijand van goden, keizers, wetten, ja, van de natuur zelve (II, 16). Ten tijde van Trajanus werd van een Christen, of omdat hij Christen was, bewezen geacht, dat hij een moordenaar, een ontuchtige, een heiligschenner en vijand des volks no. 1 was en daarom alle straffen tegelijk verdiende (II, 4). Maar noch het volk noch de rechters deden de minste moeite, deze misdaden ook werkelijk aan het licht te brengen". Dat is het nu, waarom Tertullianus zegt: laten wij niet onverhoord veroordeeld worden; dit is de miskenning, die hij niet verdragen wil. Maar de wetgever, zoo zeide het Romeinsche publiek, zou de Christenen als zoodanig niet aldus getroffen hebben, indien hij de bewijzen van hun misdadigheid niet in handen had gehad (ad nat. I, 6). Alles was reeds beslist wanneer de beschuldigde had uitgeroepen: Christianus sum. Hij zeide dit om zijn onschuld te bevestigen. Het offer, dat men hem noodigde te brengen voor het heil van den keizer, was niets dan een proef om hem te dwingen te bekennen of te verloochenen (IX, 15; XXVII, 2). Verder werd er niets gevraagd. De bekentenis dan bewees voot den rechter juist de schuld (I, 1; II, 3). "Iit een en ander volgde, dat de Christenen zich dus voor het tribunal niet $\mathrm{k}$ on d e $\mathrm{n}$ rechtvaardigen; en in de tweede plaats, dat $z \mathrm{ij}$, vetoordeeld om hun geloof, om hun naam en meer niet, als t e r e c h t veroordeeld golden, schuldig aan misdaden, waaraan $z \mathrm{ij}$ in 
werkelijkheid vreemd waren; maar dit kon nooit bewezen worden. In de oogen der heidenen waren zij dus ook niet martelaren voor een geloofsovertuiging, maar eenvoudig misdadigers".

Dit krenkte Tettullianus en hij wilde nu door middel van het Apologeticum doen wat de beschuldigden viva voce niet konden doen. Hij deed zich verhooren. Vandaat de vorm van een verweerschrift, een pleidooi voor een tribunal, niet voor een bepaalden rechter (I, 1; XXIII, 4, 5), maar voor de provinciale gouverneurs in het algemeen. Hij behandelt achtereenvolgens alle populaire beschuldigingen en toont aan, dat ze laster zijn. Wanneer aldus de onschuld der Christenen aan het licht is gebracht, moet ook aan het licht komen, dat de we $t$, die hun bestaan verbiedt, op zich zelf on recht is. Recht zou zijn den Christenen te veroorloven, hun God te aanbidden, den eenig waren, gelijk men aan alle volken toestaat hun valsche goden te vereeren (XXIV, 5-10). Tertullianus weet heel goed, dat de rechters dit niet zullen doen; dat de onrechtvaardige wet, waaraan zij vast zitten, niet afgeschaft zal worden en dat de vervolgingen zullen blijven voortwoeden. Maar na de rechters, wil hij met zijn pleidooi ook nog trachten het geweten van het publiek te bereiken, het heidensche en het Christelijke, want hij weet ook dat, indien de waarheid aan het licht komt, indien de geheele wereld ziet wat de Christenen zijn, indien hij de eer van zijn broeders vermag te redden, hij dezen zoodoende bevestigen zal in hun geloof en alle ernstige beoordeelaars, die door het heldhaftige volhouden der geloofsgetuigen reeds telkens tot nadenken zijn gebracht, zal winnen. Dit doel van zijn verweerschrift formuleert hij zoowel in het exordium als in de peroratie.

Wanneer de zaken zoo gestaan hebben, kunnen wij dan eigenlijk wel van Christenvervolgingen in deze periode van de geschiedenis spreken? Behalve op een aantal andere gegevens, waarvan er sommige reeds genoemd zijn, berust de traditioneele opvatting, die deze vraag bevestigend beantwoordt, op de meening, dat er een wet bestaan heeft van den inhoud, althans de strekking: non licet esse vos, waarvoor vooral Ap. IV, 4 als bewijsplaats wordt aangehaald. De pleiter zegt daar, met de onderstelde rechters als wetgevers en uitvoerders van de wet te willen discussieeren. Daarop volgen de woorden: iam primum cum dure definitis dicendo: non licet esse vos, etc. De beroemde codex Fuldensis leest hier voor dure: iure. Gezien het gezag van beide lezingen is het moeilijk, aan een van de twee de voorkeur te geven. Dure schijnt de uitspraak dat er een ius bestaan heeft, te willen verzachten. Moet ius vallen, dan blijft toch definitis nog als term een bepaalde kracht behouden. Bij een groot aantal historici, die iure lezen, geldt de plaats als bewijs, bv. bij Allard, Neumann, Linsenmayer, Gobbio, en Duchesne, Callewaert, Batiffol, Waltzing en bij den laatsten commentator van Tertullianus Jos. Lortz. ${ }^{4}$ ) Post in den nieuwen druk van het Handboek van Kardinaal

4) J. LoRtz, Tertullian als Apologet, Bd II, 1928, Exkurs I, S. 206-221. 
De Jong spreekt hier van de oude opvatting. ${ }^{5}$ ) Allen erkennen, dat ons geen bepaalde wetstekst van dien aard bekend is. Maar er zijn paralellen te noemen. Origenes, hom. 9 in Jes. Nave: reges terrae, senatus populusque et principes romani ... decreverunt . . . legibus suis, ut non sint Christiani. Mart. Pionii (250), VI,5: ouk eksestin hymas zên. Acta Apollonii (184) 13 en 23: to dogma tês sygklêtou estin Christianous mê einai.

Op deze paralellen mag men intusschen niet te veel nadruk leggen: de plaats bij Origenes bevat geen wetsformuleering; die in het Mart. Pionii beteekent zooveel als: zulke menschen als gij moesten er niet mogen zijn. Beide teksten zijn een halve eeuw jonger dan het Apologeticum. De Acta Apollonii geven een oncontroleerbaar bericht. Er is echter nog een andere plaats. Lactantius vermeldt, ${ }^{\circ}$ ) dat de rechtsgeleerde Ulpianus in het zevende boek van zijn werk over het ambt van den proconsul de nefaria rescripta der keizers bijeengebracht heeft om aan de hand daarvan te leeren, met welke straffen degenen, die zich zelf als vereerders van God beleden, gestraft dienden te worden. Helaas is dit boek verloren. Maar de korte inhoudsopgave kan reeds bijna als voldoende gelden om juist het tegendeel van wat men wilde bewijzen, aan te toonen. Ulpianus sprak van rescripten, hij kent blijkbaar geen algemeen geldende en overal en altijd toe te passen bepalingen. Van ouds heeft dan ook de vraag, of er een algemeene wet tegen de Christenen bestaan heeft, verschillende beantwoording gevonden. Le Blant en Profumo gaven een ontkennend antwoord. Niemand minder dan Mommsen heeft betoogd, dat zulk een wet in het Romeinsche rechtsbestel zelfs niet heeft kùnnen bestaan. In den laatsten tijd vindt deze opvatting nieuwen aanhang, zoo bij den grooten duitschen kerkhistoricus Lietzmann ${ }^{7}$ ) en in het handboek van Holmquist-Norregaard. ${ }^{8}$ ). Wij willen trachten aan te toonen, dat zij de eenig houdbare is en wel door eenvoudig enkele van de bekende teksten nog eens nader aan te zien.

De rechtsvraag der Christenvervolgingen stond omstreeks het jaar 112 voor den reeds genoemden stadhouder van Bithynië volstrekt niet vast. Derhalve verzocht hij keizer Trajanus om de noodige aanwijzingen. Hij kende geen echte Christenprocessen en wist daarom ook niet of op het bewijs, dat iemand tot het Christendom behoorde, eo ipso straf moest volgen, dan wel of er een onderzoek moest worden ingesteld naar misdrijven, die met deze gezindheid samenhingen. In deze onzekerheid had Plinius zelf van formeele procedures afgezien en getracht, de verdachten tot verloochening te brengen. Romeinsche burgers had hij verwezen naar de keizerlijke rechtspraak te Rome zelf. Ook onder

5) J. DE Jong, Handboek der Kerkgeschiedenis, 4de dr. door R. R. Post, dl. 1a, Utrecht-Nijmegen, blz. 67 vlgg.

b) Lactantius, Inst. Div., I, 11, 18-19.

7) H. LietzmanN, Geschichte der alten Kirche, Bd. 2, Berlin-Leipzig 1936, S. $156 \mathrm{ff}$.

8) H. Holmquist og J. Norreganrd, Kirkehistorie, 1. Halvbind, Kobenhavn 1946, $21,22$. 
foltering had hij nooit iets slechters dan prava et immodica superstitio kunnen ontdekken. Onbevredigd met deze methode, vraagt hij nu van den keizer nadere aanwijzingen. Van belang was de zaak wegens het groote aantal Christenen, die zich thans in een onzekeren rechtstoestand bevinden. Hun beweging bloeide ondertusschen niet alleen in de steden, maar overstroomde ook reeds de dorpen en het land, doch was misschien nog te keeren, want aan den anderen kant was ook een toename van den overgeleverden cultus te constateeren.

Trajanus antwoordde op deze vragen, dat er geen algemeene bepalingen gegeven kunnen worden. Men moet niet ambtelijk de Christenen opsporen (conquirendi non sunt); is eenmaal een aanklacht ingediend, dan moet er c.q. gestraft worden wegens ongehoorzaamheid, doch met dien verstande, dat ieder, die zijn Christendom afzweert en deze afzwering door een offer aan „onze goden” bevestigt, gratie verkrijgt. Op anonyme aanklachten gaat men niet in, deze zijn pessimi exempli en in strijd met den geest des tijds.

Uit deze correspondentie blijkt duidelijk, ${ }^{9}$ ) dat men noch in de Bithynische stadhouderlijke kanselarij noch in het keizerlijk secretariaat te Rome juridisch materiaal ter beschikking had om de door Plinius opgeworpen vraag vlot te beantwoorden; m.a.w. het bestond niet. En in de tweede plaats, dat Trajanus niet van zins was om een principieele, bindende beslissing te nemen, daar hij de onoverzienbare gevolgen niet alleen vreesde, maar ook de rechtmatigheid betwijfelde. Plinius ontvangt niet anders dan een aanwijzing in overeenstemming met de tot hiertoe gevolgde administratieve practijk. Deze liet het geloof der Christenen voor wat het was, maar eischte van de verdachten, dat zij hun politieke betrouwbaarheid toonden door te offeren voor de beelden van goden en keizers. Wie hieraan niet voldoen kon, was schuldig aan een tekort aan eerbied jegens de majesteit des rijks, des keizers en der beschermgoden en werd daarom met den dood gestraft. Bij deze practijk is het gebleven. Tertullianus heeft haar juridischen vorm scherp ironisch gegispt (II, 8).

De martelaarsacten leveren hetzelfde beeld op, veelal vermeerderd met een al of niet historische discussie, die de veroordeeling voorbereidt. In verschillende acta beroept de rechter zich wel uitdrukkelijk op keizerlijke uitspraken: Acta Carpi etc. II, (10): sacrificate, ita enim iussit imperator. Carpus dixit: vivi mortuis non sacrificant. Zoo ook in de Acta Justini, V, 8; in de Acta Pionii III, 2 is prake van een diatagma des keizers om te offeren. Dit zijn echter algemeene bepalingen, die zich niet speciaal tegen de Christenen richten en daarom geen bewijzen tegen hetgeen wij boven concludeerden. De door Justinus overgeleverde correspondentie tusschen Minucius Fundanus, stadhouder van Asia en keizer Hadrianus ${ }^{10}$ ) zegt ook, dat de zaak niet onderzocht diende te worden

) Weber, Festgabe $f$, Karl Müller, 1922, S. $26 \mathrm{ff}$.

10) Eusebius, h.e. IV, 9. 
opdat er geen onrust onder het publiek zou komen doordat de sycophanten succes kregen. Indien blijkt, dat de Christenen iets tegen de wetten, maar dat zijn de crimineele wetten, doen, dan moet er gevonnist worden overeenkomstig de schuld. Tegen de echtheid van dezen tekst zijn ernstige bezwaren in te brengen. ${ }^{11}$ ) Hoe ook beredeneerd, er zal echter altijd dit van overblijven, dat geen godsdienstwet het Christenzijn als zoodanig verbood; de schuld moest langs crimineelen weg vastgesteld worden. Hier blijkt ook duidelijk, dat de beschuldigingen een zaak van volkshaat zijn. Een en ander stemt overeen met de feiten ons uit andere bronnen bekend.

De volkshaat leeft duidelijk in het martyrium van Polycarpus van Smyrna (156). Op aandrang van het volk arresteert hem de proconsul; de grijze bisschop wordt in het stadion gebracht en de proconsul vraagt hem te zweren bij de tychê van den keizer, kyrios kaisar te zeggen, Christus te lasteren en zoo het volk te voldoen (VIII, 2; IX, 2). Polycarpus antwoordde, dat hij Christen was. De Joden, die gaarne de aandacht van zich afwentelen, hielpen bijzonder ijverig mede, zijn brandstapel hoog te maken.

Het groote martyrium te Lugdunum en Vienna aan de Rhône in 177 onder Marcus Aurelius ${ }^{13}$ ) heeft ook plaats, aangewakkerd door den volkshaat. Huizen, thermen en markten worden aan de Christenen ontzegd, die hun medeburgers om zoo te zeggen niet meer onder de oogen mochten komen; als vijanden des volks werden ze slachtoffer van schelden, plundering, steeniging, vrijheidsberooving en wat al niet meer. De eigenlijke vervolging speelt te Lyon in de Lugdunensis, waartoe de legaat de medewerking van zijn collega der Narbonnensis, waarin Vienne ligt, moet hebben verkregen. Vrijwel hoofd voor hoofd verklaren de gevangenen, dat onder hen geen misdrijven geschieden. $\mathrm{Zij}$ zijn daarvan dus beschuldigd, deze zijn de motiveering van den haat, de oorzaak van het volksoproer, dat niet slechts dreigt maar gaande is. Het antwoord is voortdurend, dat men Christen is en dit wordt dan het punt, waarop de legaat insisteert. Als overal wordt het door de Christenen zelf uitgelokt. In strijd met het rescript van Trajanus aan Plinius worden de Christenen, als betrof het een geheel nieuw geval, van overal opgespoord, zoover heeft de aandrang des volks den gouverneur, die nu aan een gevaarlijke illegale actie gaat gelooven, gebracht. Een van de slachtoffers is een Romeinsch burger, afkomstig uit Pergamon. Ten aanzien van hem vraagt de legaat hoe te handelen. Hij heeft geen algemeen geldende wet bij de hand. Het antwoord van den keizer komt geheel overeen met dat van Trajanus, waaruit blijkt, dat er althans een traditie is gevormd: zij die volhouden, moeten onthoofd, zij die afzweren, vrijgelaten worden; onthoofding heeft te Rome plaats en de straf voor de niet-Romeinsche burgers, die volharden, is dat zij voor de dieren geworpen worden.

11) Callewaert, Revue d'hist. et de litt. relig., 8, 1903, p. 152-189.

12) Eusebius, h.e., V, 1-2, 8. 
Zoo weinig doeltreffend blijkt echter het rescript te zijn, zoo volkomen is de legaat politiek in de macht van het volk, dat hij ook Attalos, den Romeinschen burger, tooi ochlooi charizomenos aan de dieren doet voorwerpen.

Als derde voorbeeld gelde de Passio ss. Scilitanorum, een zestal mannelijke en vrouwelijke bloedgetuigen te Scili in Numidië in 180, de oudste ons bekende Africaansche martelaren. $\mathrm{Z} i \mathrm{ij}$ ontkennen misdrijven op hun geweten te hebben, waren daarvan dus beschuldigd, en verklaren den keizer te eerbiedigen, doch niet verder te willen gaan: honorem Caesari quasi Caesari, timorem autem Deo, aldus maken zij een klassiek geworden onderscheiding met de motiveering: Christiani sumus. Maar de proconsul stelt daartegenover: ook wij zijn religiosi, onze religio is simplex, wij zweren bij den genius van onzen heer den keizer en smeeken voor zijn heil. Het vonnis, dat niet uitblijft en in de Passio werkelijk afgeschreven is uit de tabulae publicae van de rechtbank, zegt, dat zij bekend hebben ritu christiano se vivere en daarbij volhard hebben, ofschoon hun de gelegenheid is geboden tot den mos der Romeinen terug te keeren.

Tenslotte nog een enkel punt uit een der beroemdste passiones, die van Perpetua en Felicitas, waarmede wij tot Tertullianus, die waarschijnlijk de redacteur is van den vorm, waarin zij werd gepubliceerd, terugkeeren; de Passio speelt in 202-203 onder Septimius Severus te Carthago. Te midden van een populus immensus tracht de vader van Perpetua gedaan te krijgen, dat zij hem als Romeinsch burger niet te schande make. De procurator noodigt haar om te offeren voor het heil der keizers. $Z_{i j}$ weigert, waarop hij vraagt: Christiana es? Het antwoord luidt: Christiana sum. Hierop volgt veroordeeling ad bestias. Een bijzonderheid bij het martelaarschap in de arena is dan, dat men de mannen, die in dit Martyrium betrokken werden, kleeden wilde als priesters van Saturnus en de vrouwen als priesteressen van Ceres. Daar protesteeren zij tegen, want zij gaan juist in den dood om n i e t tot dergelijke dingen gedwongen te worden. Dit juiste argument wordt erkend door den procurator, die een goede Romein blijkt en dan van verder toegeven aan de wenschen des volks ook afziet.

Wanneer wij nu deze gegevens samenvatten, komen wij tot een vrij ongecompliceerd resultaat. Geen wet geeft een onveranderlijken hoofdtoon aan. In meer dan een geval vraagt de provinciale gouverneur richtlijnen, zooals men dit tegenwoordig noemt, te Rome; deze komen dan neer op niet-opsporen, maar wel straffen, indien de Christenen volharden in hun weigering om te doen wat van een goed burger gevergd wordt. Uit alle gegevens blijkt, dat het de volksmassa is, die de ongeregeldheden provoceert, dat het volk bevredigd moet worden en dat de gouverneur tegen den machtigen drang van het volk niet op kan en willekeur in plaats van recht oefent.

Drie vragen volgen hieruit en als wij deze kunnen beantwoorden Teo. 4 
hebben wij ook het onderwerp, dat wij ons voorstelden, toegelicht, voor zoover de gegevens zulks mogelijk maken.

1. Wat is het werkelijke conflict tusschen de Christenen en het overige volk geweest?

2. Wat is het werkeijke conflict tusschen de Christenen en hun competente rechters, resp. den Romeinschen staat?

3. Hoe handelde de overheid met de Christenen?

Ad 1. Het conflict was noch gemaakt noch gezocht, maar vond zijn wortel in de geloofsovertuiging der Christenen en kwam tot uiting in hun sociaal-politiek gedrag, op welk gedrag het volk den aanval richtte. Het Christendom $^{1}$ ) heeft zonder bijzondere middelen in het werk te stellen, gedurende de tweede eeuw een geweldige aantrekkingskracht uitgeoefend. Los van de synagoge, die het trouwens begon te bestrijden ${ }^{2}$ ) vond het zijn eigen onafhankelijken-weg, gesteund door de vervulde profetieën van het Oude Testament. Dit gaf achtergrond en stijl. De betekenis van het Evangelie voor geloof en ethiek was voorts onuitputtelijk. De kracht tot de verbreiding lag in de aanraking met Christus en in den Geest. Het resultaat voor de practijk des levens was een critische houding t.o.v. vele uitingen van het sociale leven en bepaalde bezigheden, vooral die samenhingen met theater, verschillende diensten en den eeredienst in meer strikten zin, later ook den militairen dienst. Tertullianus, die aan den preciesen kant stond en steeds verder zou gaan, zegt in de Apologie nog: wij zijn geen Brahmanen, of Indische gymnosophisten, boschbewoners, die buiten het leven staan. Wij weten dank verschuldigd te zijn aan God den Heer en Schepper; geen enkele vrucht van $Z$ ijn werken wijzen wij af, maar wij kennen grenzen om ze niet zonder maat en zin te gebruiken. Derhalve doen wij het niet zonder uw forum, uw vleeschmarkt, badhuizen, winkels, werkplaatsen, gasthuizen, weekmarkten en op allerlei andere wijzen zijn wij met dit saeculum verbonden. $W_{i j}$ varen als gij ter zee, doen krijgsdienst, beoefenen landbouw en koophandel; onze handwerken stellen wij ook in uw dienst (XL, 1, 3). Met deze woorden wijst hij de beschuldiging af, dat de Christenen publici hostes zijn en infructuosi negotiis. Hier ligt nu juist het conflict tusschen hen en hun heidengebleven volks- en landgenooten: door hun godsdienstige levensopvatting is er niettemin een diepgaande, innerlijk gemotiveerde en in de uiterlijke dingen niet meer te overbruggen tweespalt gekomen; en deze tweespalt tusschen de burgers is opgevoerd tot een conflict tusschen de Christenen en den staat. Dat wordt zeer begrijpelijk als men maar eenmaal heeft ingezien, dat er aanleiding genoeg scheen te bestaan om de Christenen met hun maatschappelijke critiek te signaleeren als onbetrouwbare burgers. Dit vond zijn eenvoudigste en meest voor de hand liggende uitdrukking in hun weigering

13) A. D. Rock, Conversion, Oxford 1933, p. 187-271.

14) Mart. Polyc. XII, 2; XIII, 1; XVII, 2; XVIII, 1. Mart. Pionii III, 6; IV, 8. T., Ap., VII, 3 etc. 
om aan den staatscultus deel te nemen, die zooals hij voor het tribunal werd geëischt meer politiek dan religie was, waarvan zij de politieke zijde in beperkten zin konden aanvaarden (honorem Caesari), maar waarmede men hen juist met hun religie in botsing wist te brengen, een manier, die natuurlijk nimmer faalde, omdat hier hun intransigentie direct voor den dag moest komen. Zoo zien wij den socialen haat tot een conflict. tusschen Christenen en niet-Christenen worden en dit tot een conflict tusschen de Christenen en den Staat. Zij waren de eersten, die, buiten de Joodsche religio licita, de keizervereering verwierpen. De overheid moest aan het geval wel aandacht schenken, omdat de aanklachten tevens altijd de beschuldiging van zware zedelijke misdrijven inhielden. Eenmaal aldus voor het tribunal behandeld, bleek spoedig genoeg, dat er juridisch van deze beschuldigingen niets overbleef. De rechter, voor zoover hij den moed had, de ongunst des volks te trotseeren, wilde den aangeklaagden wel gaarne de vrijheid hergeven en hij trachtte dit te doen door hen door middel van een offertje te laten toonen, dat zij goede burgers waren. Doch door dit nauwe poortje wenschten de Christenen den breeden weg niet te betreden. Hier bleven zij voor staan en zoo kreeg hun proces den schijnvorm van een godsdienstproces, hetgeen zij zelf zochten.

Ad 2. Het conflict van de Christenen met den staat en de rechters was dus, dat zij den openbaren cultus verwierpen en ongehoorzaam bleven aan hetgeen men van hen eischte, zodat de oorzaak der ongeregeldheden niet werd weggenomen. Ook dit brengt Tertullianus weder scherp onder woorden (XXIV, 1, XXVIII ss.). Wat voor den dag komt als Christenen voor het tribunal staan, is: crimen laesae publicae et maxime romanae religionis, volgens welke formuleering beleediging van of gebrek aan eerbied voor de dii populi romani als beleediging en schade der Romeinsche natie golden, die onder het crimineele recht vielen en kapitale straf eischten. De term majesteitsschennis was juist, maar niet gangbaar; de andere term sacrilegium (atheotês) was gangbaar, maar niet juist. Laedimus Romaros, nec Romani habemur qui nec Romanorum deum colimus (XXIV, 10). Dit is de tweede titel voor de veroordeeling der Christenen: laesae augustioris majestatis, nl. der majesteit van den keizer, die zwaarder weegt dan gebrek aan eerbied voor de goden, want de keizer is om zoo te zeggen de dichtstbijzijnde, de meest reëele godheid. Dit conflict is algemeen bekend. De keizercultus was voor den Romein allesomvattend en eeuwig, zooals het imperium zelf. $\mathrm{Hij}$ was daarom een machtig element in de politiek om de verschillende volkeren, die onder het imperium waren gebracht, tot een levende, geestelijke eenheid te doen worden, die niet alleen op uitwendige kracht, maar ook op den goeden wil en de instemming van de onderdanen moet berusten. Wie deze orde verbrak trad revolutionnair op, toen de keizercultus eenmaal staatscultus was geworden. Deze cultus was bestemd om twee dingen te bewerkstelligen: het imperium te omspannen als politiek universum en 
in de tweede plaats dit politieke universum tot een innerlijke, geestelijke, godsdienstige aangelegenheid der volkeren te doen zijn, waaraan een ieder persoonlijk en zichtbaar cultisch had deel te nemen. Naast andere eerediensten mocht deze nooit officieel verwaarloosd worden en wie van gebrek aan loyaliteit verdacht werd, moest door een eed of offer toonen, dat hij. betrouwbaar was. Goed Romeinsche tolerantie deed den magistraat dan zeggen: gij moogt uw goden wel vereeren, maar ook den keizer moet gij eeren. Acta Cypriani 258 Sept. 14: imperatores ... praeceperunt eos qui romanam religionem non colunt, debere romanas caeremonias recognoscere. Dit weigerden die Christenen, die van het martelaarshout als de groote bisschop Cyprianus waren gesneden. Het gold naar Romeinsch besef slechts de natuurlijke goden, ${ }^{1}$ ) waarvan het vanzelf sprak, dat elke Romein ze eerde. Dezen politieken weg wilden de Christenen niet op; hun God is een naijverig God, hun monotheistische religie is even exclusief en even totalitair als de Romeinsche politiek. Op dat terrein werd hun conflict met den staat gebracht en dit heeft Tertullianus zoo scherp mogelijk onder woorden gebracht (XXIV, 10). Maar aan den anderen kant heeft hij ook gelijk als hij in goed Romeinschen geest in een ander geschrift zegt: non religionis est religionem cogere (Ad Scap. 2). Het gold hier echter minder religie dan wel politiek, met name burgerlijke gehoorzaamheid en dus werd er wel gedwongen. Zoo was de practijk.

Ad 3. Hoe handelde nu de overheid juridisch met de Christenen? De magistraat maakte van zijn ius coercitionis gebruik. Dit sprak vanzelf. Van de drie rechtscategorieën, die wij in het oude Rome kennen, het privaat, het publiek en het godsdienstig of sacrale recht, is het laatste, waaraan godsdienstige overtreding, bv. het verwaarloozen van de offers, beantwoordde als onhoudbaar spoedig verdwenen. ${ }^{2}$ ) Het recht van doodstraf en zware boete ging op den staat over; ingrijpen in sacrale aangelegenheden kon trouwens geen burger. In het historische Rome bestond geen sacraal delict en geen algemeen sacraal proces meer. Godsdienstig misdrijf viel nergens onder. Vandaar de regel: deorum iniuriae diis curae. En: nolo mihi lovem propitium esse; tu quis es? me conveniat Ianus iratus ea qua velit fronte! quid tibi mecum est? (T. Ap XXVIII, 1). Ook onder de categorie der schennis van de majestas populi romani valt het niet. Wie deze bedreef, heet atheos, waarvoor het latijn geen woord bezit, wat bewijst, dat dit begrip oorspronkelijk vreemd is aan het Romeinsche rechtsbewustzijn. Spreken en schrijven tegen den staatsgodsdienst is dan ook nooit onder dit crimen gebracht, als was het nog zoo lasterlijk. De wet begraf zich niet op dit terrein. Treedt nu de Romeinsche rechter op tegen een Christen, dan gaat het niet om den godsdienst, maar om allerlei crimina, anders is de rechter niet in beweging te brengen. Dit wist het volk en beschuldigde daarom maar raak. Deze

15) EuseBIUs, h.e., VII, 11, 6 epi to kata physin trepesthai.

16) Тн. Mommsen, Der Religionsfrevel nach röm. Recht, Hist. Zeitschr. 64, 1890, S. 389. Röm. Strafrecht, IV, 1, Abschn. 85. 
crimina waren echter niet te bewijzen. Als gij ons dan toch veroordeelt zegt de jurist Tertullianus, dan doet gij het enkel om ons nomen Christianum en dit is onromeinsch, in strijd met alle begrip van Romeinsch recht (XL, 4). Daarin had hij gelijk. De Christen viel dan subjectief, naar zijn eigen besef, als Christen, dus voor zijn geloof, maar voor het besef van den Romeinschen rechter is hij alleen maar een halsstarrige, die, als hij dan al onschuldig is aan de bedoelde crimina, toch geen loyaliteit wil toonen door te offeren. De magistraat trad hierin niet crimineel, maar politioneel op. Het behoorde tot zijn bevoegdheid om de coercitio toe te passen, een ius, dat alle magistraten bezaten, die met de potestas en dus vooral zij, die met het imperium bekleed waren. Het beteekende de macht om te dwingen tot gehoorzaamheid aan hetgeen de magistraat voorschreef. Het was geen juridisch recht of oordeel, maar gaf uitdrukking aan het recht der gemeenschap en haar orde in disciplinairen zin tegenover den individueelen burger. Hier kon het persoonlijk optreden van den ambtenaar beslissend zijn. Hij kon handelen onder invloed van het volk - voorbeelden te over - of wel hij kon zich daarboven stellen en directieven te Rome vragen - ook hiervan zagen wij voorbeelden. De coercitio behoorde niet onder de publica iudicia, maar wel onder de officia proconsulis, die Ulpianus in het verloren gegane VIIde boek moet hebben opgesomd. Op dit administratief-disciplinaire terrein nu werden kwesties met een religieuzen kant gebracht. Het is volkomen terecht, wanneer de Apologeten de juridische conclusie afdwingen, dat de overheid niet het Christelijk geloof als misdrijf beschouwt en wanneer Tertullianus in het bijzonder het juridisch absurde doet zien van het feit, dat het hier in de practiek toch op neerkwam. De scherpste wending in zijn pleidooi blijft de uitroep: dure definitis: non licet esse vos. Dit $\mathrm{w}$ a $\mathrm{s}$ de wet niet, maar gezien de coërcitiopractijk had dit de wet moeten zijn, dus hij onderstelt die wet, hij dringt a.h.w. den rechters op, dat zij die wet hebben, zij handelen althans zoo, maar zij hebben haar in werkelijkheid niet. Dit is Tertullianus' manier om op hun rechtsgevoel te appelleeren; hij laat hen door zijn definitie als in een spiegel zien iets waarvan ze behooren te schrikken met den wederuitroep: Doen wij dit? Dit willen wij niet! Het appèl kon echter niet meer baten; het gebruik had al te zeer beslag op de gouverneurs gelegd om nog zelfstandig en goed juridisch te kunnen redeneeren tegenover de oproerige plebs. Naarmate de verbreiding van het Christendom toenam, moest het meer en meer het voorwerp van politieke repressie worden in dezelfde mate, als de ontwikkeling van de godsdienstige Romeinsche staatsgedachte in vulgairen zin toenam. Daar het Christendom vooreerst echter $\mathrm{r}$ elig $\mathrm{i}$ e bleef en nog niets anders wilde zijn, kunnen wij ook voor dezen tijd, doch alleen op voorwaarde, dat men de geheele lange redeneering, die wij hier gehouden hebben, onderstelt, van Christenvervolgingen blijven spreken. 